\title{
Cultural variation in early feeding pattern and maternal perceptions of infant growth
}

\author{
Manon van Eijsden $^{1 *}$, Claire M. C. Meijers ${ }^{2}$, Jessica E. Jansen ${ }^{2}$, Marlou L. A. de Kroon ${ }^{3,4}$ \\ and Tanja G. M. Vrijkotte \\ ${ }^{1}$ Department of Epidemiology and Health Promotion, Public Health Service of Amsterdam, PO Box 2200, \\ 1000 CE, Amsterdam, The Netherlands \\ ${ }^{2}$ Department of Child Health Care, Public Health Service of Amsterdam, Amsterdam, The Netherlands \\ ${ }^{3}$ Department of Public Health, VU University Medical Center (VUmc), Amsterdam, The Netherlands \\ ${ }^{4}$ Department of Public Health, Erasmus MC, University Medical Center Rotterdam, Rotterdam, The Netherlands \\ ${ }^{5}$ Department of Public Health, Academic Medical Center, University of Amsterdam, Amsterdam, The Netherlands \\ (Submitted 4 April 2014 - Final revision received 6 February 2015 - Accepted 3 March 2015 - First published online 13 July 2015)
}

\section{Abstract}

The perception of healthy growth and weight may differ between cultures, which could influence feeding practises and consequently affect the development of overweight. The present study examined ethnic variation in maternal perceptions of growth and their influence on feeding practises among Turkish and Dutch infants aged 0-6 months. Data were obtained from the mothers of 143 Turkish and 143 Dutch healthy, singleton, term infants with birth weights appropriate for gestational age, using structured interviews at 1 , 4 and 6 months after birth. Compared with Dutch mothers, mothers of Turkish descent perceived a chubby infant more often as pretty ( $43 v .22 \%$ ), and were more often worried about their infant's growth (13v. 4\%). Turkish mothers were more likely to give full breastfeeding (BF) until at least 6 months (adjusted OR (aOR) 2.1, $95 \%$ CI 1.0, 4.3) and to start introducing complementary feeding, including rice flour porridge, at the age of 6 months (aOR $2 \cdot 4,95 \%$ CI 1.1, 4.9). Infants of Turkish descent were fed on average one milk feeding more during the day and, if introduced to complementary foods before 6 months, were more often given uncommon types of foods (e.g. yogurt and cookies) (aOR 2·1, $95 \%$ CI 1·1, 4.3). The differences in perceptions affected differences in feeding practises only to a small extent. Preventive advice offered to Turkish mothers in Child Health Care should include discussing choices of complementary foods and frequency of feeding from an early age onwards. In Dutch mothers, support for the continuation of BF remains an important issue.

Key words: Breast-feeding: Complementary feeding: Ethnicity: Perceptions

Childhood overweight and obesity have become an epidemic problem affecting various ethnic groups worldwide ${ }^{(1)}$, with prevalence rates varying from $15 \%$ up to $45 \%$ for Europe, North America and Australia ${ }^{(2)}$. Since childhood obesity tracks into adulthood and affects the risk of development of cardiometabolic ill health ${ }^{(3-5)}$, there is great concern for future health and healthcare.

Minority groups are at a higher risk of developing childhood overweight or obesity than others ${ }^{(6-10)}$. In The Netherlands, the highest prevalence of overweight (including obesity) is reported among children and adolescents of Turkish descent (>30\%), and obesity rates for this group are four to five times higher than for native Dutch children ${ }^{(11,12)}$. Moreover, recent studies have suggested that cardiovascular risk factors are more strongly affected by overweight and obesity in Turkish children than in peers of other ethnic descent ${ }^{(13,14)}$.
Increasing evidence points to the role of early life nutrition in the development of overweight and obesity. Both duration of breast-feeding (BF) and timing of introduction to complementary foods are feeding practises with an impact on early growth and subsequent overweight and obesity ${ }^{(15-18)}$, although the evidence is not conclusive ${ }^{(19,20)}$.

Some studies have reported ethnic differences in feeding practises, with Turkish mothers generally showing a high prevalence of $\mathrm{BF}$, but also early introduction of complementary foods, topping up BF with formula feeding and using food for infant comforting ${ }^{(21-24)}$. These ethnic differences in feeding practises could be influenced by cultural variation in the perception of growth. Turkish parents in The Netherlands were found to prefer infant growth above the national average $^{(24)}$ and generally consider overweight in toddlers as a sign of prosperity and good caregiving ${ }^{(25)}$. Moreover,

Abbreviations: BF, breast-feeding; CF, complementary feeding.

*Corresponding author: M. van Eijsden, email mveijsden@ggd.amsterdam.nl 
mothers, in general, tend to underestimate the weight of their overweight child $^{(26)}$, and Turkish mothers are even almost three times more likely to do so than Dutch mothers ${ }^{(27)}$.

The present study will compare the feeding pattern of Dutch and Turkish infants aged 0-6 months, and will examine the role of maternal perceptions of infant growth. More knowledge of feeding practises among Turkish mothers is essential to support effective interventions in Child Health Care and may help combat the large ethnic disparities in childhood overweight and obesity.

\section{Methods}

\section{Study population}

The present study population includes Turkish and Dutch mothers and their infants, born between August 2009 and March 2010 in five districts of Amsterdam. Infants were considered of Turkish descent if at least one parent and the mothers' mother were born in Turkey. Infants were of Dutch descent when both parents and the mothers' mother were born in The Netherlands. Inclusion criteria were term gestational age ( $\geq 37$ weeks), appropriate weight for gestational age ( $\geq 10$ th percentile of Dutch national reference curves), singleton pregnancy, no maternal complications during pregnancy (e.g. no diabetes or hypertension) and no infantile medical problems diagnosed during pregnancy or after birth (e.g. congenital malformations).

Approximately, 2 weeks after birth, when data on ethnicity, pregnancy, birth and neonatal health were recorded in the Child Health Care registration, mothers with infants meeting the inclusion criteria were contacted by phone. Verbal and written study information was provided. Once participation was agreed, a home visit was made 4 weeks after birth during which written informed consent was obtained. Nowhere in the study information was reference made to the association between infant growth and health. Mothers were merely informed that the study aimed to map the growth of infants in Amsterdam and examine factors that may be relevant. In total, 368 mothers were asked to participate, of whom 300 (150 Dutch and 150 Turkish) agreed (81.5\%). As mothers were approached in the Turkish language whenever required, no substantial differences were seen in response rates between the Turkish and Dutch groups $(80 \cdot 2 v \cdot 82 \cdot 8 \%)$. All participants were informed extensively about the purpose of the follow-up procedure, which included three home visits (1, 4 and 6 months after birth). In both ethnic groups, completion rate was high (95\%); reasons for not completing the study included changing address, lack of time or being unreachable. The final study sample consisted of 286 participants (143 Dutch and 143 Turkish). All participating mothers provided informed consent. The study protocol was approved by the Medical Ethical Committee of the Academic Medical Centre in Amsterdam, The Netherlands.

\section{Questionnaire}

At each home visit, participating mothers were interviewed according to standard questionnaires, covering infant feeding pattern, perception of infant growth and sociodemographic characteristics. Home visits were made by a team of ten medical students, who were carefully selected and extensively trained to secure the comparability and quality of the data. Half of these students had a Turkish background and were able to speak Turkish if requested by the mother.

\section{Infant feeding pattern}

Mothers were asked to provide information on the feeding pattern of their infant at each home visit. Feeding items included BF, formula feeding, the use of rice flour (added to formula or BF to make porridge) and complementary foods. For each food item, the interviewer recorded whether the child had received it in the period preceding the visit and the duration. For the present study, we calculated the duration of full $\mathrm{BF}$ in four categories ( $<1$ month, 1-4 months, 4-6 months and $\geq 6$ months) on the basis of the duration of $\mathrm{BF}$ and start of formula feeding. Furthermore, we used two definitions in calculating the age (in months) at introduction of complementary feeding (CF): (1) introduction of CF including rice flour porridge; (2) introduction of $\mathrm{CF}$ excluding rice flour porridge. Following Dutch guidelines for the introduction of $\mathrm{CF}^{(28)}$, we categorised the introduction of $\mathrm{CF}$ for both definitions in three categories: $<4$; 4-6; $\geq 6$ months. We also determined the types of complementary foods given to the infant (fruits, vegetables, yogurt, cereals and starch foods; confectionary; or other types of food) and categorised mothers as providing uncommon CF before 6 months of age (yes/no). Uncommon complementary foods in the present study were defined as yogurt, bread, cereals and starches; confectionary; and other foods (e.g. soup, meat and cheese) that are not vegetables, fruits or rice flour. Lastly, we calculated the frequency of feeding for both milk feeding and CF at 1 month (only milk feeding), 4 and 6 months.

\section{Perceptions of infant growth}

To asses maternal perceptions of infant growth, mothers were asked how they felt about the growth of their baby at the third home visit: adequate; too slow; too fast. In addition, mothers were asked to respond to two propositions: (1) I perceive a chubby baby as prettier than a thin baby; (2) I perceive a chubby baby as healthier than a thin baby. Answers were given on a 5-point Likert scale, which we recoded into three categories: do not agree; neutral; agree.

\section{Maternal and infant characteristics}

Parity (primiparity/multiparity), cohabitant status (parents living together or not) and maternal employment status (employed/not employed) were recorded at the first home visit. Maternal educational level was recorded during the second home visit, at 4 months, and divided into three categories: low (primary school or less, lower vocational education or lower general secondary education); middle (higher general secondary education, pre-university education or intermediate vocational education); high (higher vocational education or university). Maternal height and weight were measured by physicians at Child Health Care Centres during 
the regular 6-month check all children receive. In total, data on 203 mothers were recorded, and BMI was calculated as weight (in $\mathrm{kg}$ ) divided by height (in $\mathrm{m}^{2}$ ). BMI was classified into three categories: normal weight (BMI $<25 \mathrm{~kg} / \mathrm{m}^{2}$ ); overweight $\left(25 \leq \mathrm{BMI}<30 \mathrm{~kg} / \mathrm{m}^{2}\right)$; obese $\left(\right.$ BMI $\left.\geq 30 \mathrm{~kg} / \mathrm{m}^{2}\right)$. Missing values on BMI ( $n$ 89) were coded as a separate category. Data on gestational age (d), birth weight (g), sex and maternal age (years, calculated on the basis of maternal birth date and infant birth date) were also obtained from the Child Health Care registration. Infant growth at the age of 6 months was measured at the Child Health Care centre. Standard deviation scores for weight, length and weightfor-length were calculated using national sex-specific reference values ${ }^{(29)}$, using the Growth Analyser Research Calculation Tools Software, version 4.0 (Growth Analyser BV).

\section{Statistical analyses}

Ethnic differences in maternal characteristics, infant characteristics, maternal perceptions and infant feeding pattern were analysed using $\chi^{2}$ and Fisher's exact tests for categorical data and Student's $t$ test for continuous data. We explored the role of maternal perceptions of growth in explaining ethnic differences in feeding pattern using regression analyses. First, we tested the proportionality assumption for ordinal regression to asses ethnic differences in the duration of full $\mathrm{BF}^{(30)}$. Since the proportionality assumption was not met, logistic regression analysis was performed to assess differences in duration of full $\mathrm{BF}$ (cumulative $\geq 1, \geq 4$ and $\geq 6$ months). Multinomial regression analysis was used to analyse the ethnic differences in introduction of CF (according to both definitions), and logistic regression analysis was used to assess the intake of uncommon complementary foods before 6 months. Lastly, linear regression was performed for the continuous outcome frequency of milk feeding and CF.

In all regression analyses, a stepwise hierarchical adjustment procedure was used. First, a crude model was analysed with only ethnicity as independent variable, the second model adjusted for confounders and the third model for perceptions of growth. We considered only those variables that were associated with ethnicity and feeding variables (cut-off value $P<0 \cdot 10)$ as confounders. No adjustments were made for maternal educational level given the high correlation with ethnicity $(-0 \cdot 75$, rank biserial correlation)

Because of small numbers, the variables for perceptions of growth were recoded to dichotomous variables (growth: too slow $v$. adequate + too fast; perceiving chubby as healthy: agree $v$. neutral + do not agree; perceiving chubby as pretty: agree $v$. neutral + do not agree). Analyses were performed with SPSS version 21.0 (IBM SPSS, Inc.), and findings were regarded as statistically significant when $P$ values $<0 \cdot 05$.

\section{Results}

\section{Maternal and infant characteristics}

Table 1 shows that Dutch mothers were generally older and less often overweight than Turkish mothers. Dutch mothers also had
Table 1. General characteristics of the study population

(Number of participants and percentages; mean values and standard deviations)

\begin{tabular}{|c|c|c|c|c|c|}
\hline & \multicolumn{2}{|c|}{ Dutch } & \multicolumn{2}{|c|}{ Turkish } & \multirow[b]{2}{*}{$P^{\star}$} \\
\hline & $n$ & $\%$ & $n$ & $\%$ & \\
\hline \multicolumn{6}{|l|}{ Maternal characteristics } \\
\hline Age (years) & 137 & & 140 & & $<0.001$ \\
\hline Mean & \multicolumn{2}{|c|}{$32 \cdot 2$} & \multicolumn{2}{|c|}{28.8} & \\
\hline SD & \multicolumn{2}{|c|}{4.4} & \multicolumn{2}{|c|}{4.8} & \\
\hline \multicolumn{5}{|l|}{ Educational level (\%) } & $<0.001$ \\
\hline Low & 5 & 3.5 & 76 & 53.1 & \\
\hline Middle & 26 & $18 \cdot 2$ & 49 & 34.3 & \\
\hline High & 112 & $78 \cdot 3$ & 18 & $12 \cdot 6$ & \\
\hline \multicolumn{5}{|l|}{ Cohabiting (\%) } & 0.282 \\
\hline No & 6 & $4 \cdot 2$ & 2 & 1.4 & \\
\hline Yes & 137 & $95 \cdot 8$ & 141 & 98.6 & \\
\hline \multicolumn{5}{|l|}{ Parity (\%) } & $<0.001$ \\
\hline Primipara & 87 & $60 \cdot 8$ & 39 & $27 \cdot 3$ & \\
\hline Multipara & 56 & 39.2 & 104 & 72.7 & \\
\hline \multicolumn{5}{|l|}{ Weight status (\%) } & $<0.001$ \\
\hline Normal weight & 68 & 68.0 & 26 & $26 \cdot 8$ & \\
\hline Overweight & 25 & $25 \cdot 0$ & 39 & $40 \cdot 2$ & \\
\hline Obese & 7 & 7.0 & 32 & 33.0 & \\
\hline Unknown & 43 & & 46 & & \\
\hline \multicolumn{5}{|l|}{ Employment status } & $<0.001$ \\
\hline Employed & 131 & 91.6 & 57 & 39.9 & \\
\hline Not employed & 12 & 8.4 & 86 & 60.1 & \\
\hline Infant characteristics & & & & & \\
\hline Sex (\%) & & & & & 0.554 \\
\hline Boy & 70 & $49 \cdot 0$ & 75 & $52 \cdot 4$ & \\
\hline Girl & 73 & $51 \cdot 0$ & 68 & 47.6 & \\
\hline Gestational age (d) & 141 & & 140 & & 0.388 \\
\hline Mean & & & & & \\
\hline SD & & 9 & & & \\
\hline Birth weight (g) & 141 & & 142 & & 0.757 \\
\hline Mean & & & & & \\
\hline SD & & & & & \\
\hline Age at home visit (months) & & & & & \\
\hline Visit 1 & 143 & & 142 & & 0.121 \\
\hline Mean & & 06 & & & \\
\hline SD & & & & & \\
\hline Visit 2 & 143 & & 143 & & 0.001 \\
\hline Mean & & & & & \\
\hline SD & & & & & \\
\hline Visit 3 & & & & & $<0.001$ \\
\hline Mean & & & & & \\
\hline SD & & & & & \\
\hline Infant growth & & & & & \\
\hline Weight (SDS) & 137 & & 136 & & $<0.001$ \\
\hline Mean & & 38 & & & \\
\hline SD & & & & & \\
\hline Length (SDS) & 139 & & 139 & & 0.132 \\
\hline Mean & & & & & \\
\hline SD & & & & & \\
\hline Weight-for-length (SDS) & 135 & & 134 & & 0.002 \\
\hline Mean & & 44 & & & \\
\hline SD & & 94 & & & \\
\hline Perceptions of growth & & & & & \\
\hline Growth of infant & & & & & $<0.001$ \\
\hline Too slow & 5 & 3.5 & 18 & $12 \cdot 6$ & \\
\hline Adequate & 131 & 91.6 & 100 & 69.9 & \\
\hline Too fast & 7 & 4.9 & 25 & 17.5 & \\
\hline $\begin{array}{l}\text { Perceiving chubby infant as } \\
\text { healthier }\end{array}$ & & & & & 0.005 \\
\hline Do not agree & 72 & $50 \cdot 3$ & 98 & 68.5 & \\
\hline Neutral & 41 & $28 \cdot 7$ & 30 & 21.0 & \\
\hline Agree & 30 & $21 \cdot 0$ & 15 & 10.5 & \\
\hline $\begin{array}{l}\text { Perceiving chubby infant as } \\
\text { prettier }\end{array}$ & & & & & $<0.001$ \\
\hline Do not agree & 55 & 38.5 & 57 & 39.9 & \\
\hline Neutral & 56 & 39.2 & 24 & $16 \cdot 8$ & \\
\hline Agree & 32 & $22 \cdot 4$ & 62 & 43.4 & \\
\hline
\end{tabular}

SDS, standard deviation score

${ }^{*} \chi^{2}$ tests or Fisher's exact test for two-by-two tables for categorical variables; Student's $t$ test for continuous variables. 
a higher educational level, and were more often employed; $60 \%$ of the Dutch mothers gave birth to a first child, compared with $27 \%$ of the Turkish mothers. The birth and sociodemographic characteristics of the infants did not significantly differ between the ethnic groups, with the exception of the infant's age at the second and third home visit. Infant weight and weight-forheight at the age of 6 months were significantly higher for Turkish infants than for Dutch infants.

\section{Perceptions of growth}

Large differences were found in maternal perceptions of growth: $13 \%$ of Turkish mothers perceived their infant as growing too slow, compared with $4 \%$ of Dutch mothers (Table 1). Interestingly, a similar difference was observed for perceiving growth as too fast. Turkish mothers rated the prettiness of a chubby infant higher than Dutch mothers (43 v. 22\%); however, Dutch mothers perceived a chubby infant more often as healthy (21 v. $11 \%$ ). Online Supplementary Table S1 shows that perceiving a chubby infant as healthy was also significantly associated with being primiparous, having a normal weight and being employed.

\section{Feeding pattern}

It is observed that $88 \%$ of the mothers started with $\mathrm{BF}$ and $72 \%$ continued to give full $\mathrm{BF}$ until at least 1 month; these rates were similar in the two ethnic groups (Table 2). Among Dutch mothers, $15 \%$ continued full BF until at least 6 months, compared with 36\% among Turkish mothers. Early ( $<4$ month) introduction of rice flour porridge was more common among Dutch mothers than among Turkish mothers. However, among the Dutch, other types of foods were generally not given until the 5 th $(50 \%)$ or 6 th months (30\%). Turkish mothers provided their infants with complementary foods either before the 5 th month (35\%) or from 6 month onwards ( $41 \%)$, which more often included unconventional foods such as (sweet) yogurt, bread and confectionary. Overall, Turkish infants were fed more frequently than Dutch infants (eight times $v$. seven times in a day), primarily in the form of milk feedings. This difference of one feeding persisted when examining only the mothers who gave full BF until 1, 4 and 6 months respectively (data not shown).

\section{Perceptions of growth in relation to feeding pattern}

Regression results in Table 3 show that the ethnic differences in feeding pattern were significant for duration of full $\mathrm{BF} \geq 6$ months, introduction of $\mathrm{CF}$ including rice flour porridge $\geq 6$ months, providing unconventional foods $<6$ months and feeding frequency at 1 and 4 months, even after adjustment for sociodemographic characteristics.

Associations between maternal perceptions of growth and the feeding pattern variables are presented in online Supplementary Table S2. Adjusting the ethnic differences for perceptions of growth slightly attenuated the association with duration of full $\mathrm{BF}$ and the intake of unconventional foods $<6$ months. The ethnic difference in the date of introduction to complementary foods including rice flour porridge was masked by maternal perceptions of growth. The full model (model 3) revealed that mothers who perceived a chubby infant as prettier were less likely to start introducing CF from 6 months onwards (OR $0 \cdot 4$, $95 \%$ CI $0 \cdot 2,0 \cdot 8$, data not presented in table). The association between feeding frequency and ethnicity was not attenuated by maternal perceptions of growth.

\section{Discussion}

In the present study, Turkish mothers showed both beneficial and adverse early feeding practices. Adjustment for maternal perceptions of growth attenuated some of the ethnic differences in feeding practises, but only to a small extent. An exception was the age at introducing CF (including rice flour porridge): here, the maternal perception of chubbiness being pretty masked the differences in feeding practices. Perceiving a chubby infant as pretty was associated with an earlier introduction of CF. However, even though Turkish mothers perceived a chubby infant as more pretty, they were less likely to start CF before 6 months than Dutch mothers. Turkish mothers also more often perceived their infant's growth as too slow. These results correspond to previous results showing that Turkish families consider overweight as a sign of prosperity and good caregiving ${ }^{(25)}$. Interestingly, however, Dutch rather than Turkish mothers more often perceived a chubby infant as healthy. Also primiparous mothers more often perceived a chubby infant as healthy. This could reflect an effect of the various initiatives that have been launched in the Netherlands and in Amsterdam specifically to combat the childhood overweight and obesity epidemic. Primiparous mothers would have been less exposed to these initiatives than multiparous women who have already visited Child Health Care for a previous child. As most Turkish mothers were multiparous, they may have become more aware of the health effects of an unhealthy weight than Dutch mothers. Yet, if they still perceive their infant's growth as inadequate, their interpretation of chubby may differ from the interpretation of Dutch mothers. Indeed, a Dutch cohort study, performed in the same time period as the present study, has shown that mothers of Turkish descent were three times more likely to underestimate the weight of their child at the age of 5 years. This emphasises the importance of creating awareness in parents about the weight and size of their infants and children, particularly in groups at risk for overweight. A visual aid may be the 'weight development card' (http:// webshop.voedingscentrum.nl/gewichtsverloopkaart.html), which has been specifically developed for that purpose.

In contrast to our expectations, Turkish mothers were more likely to give full BF (i.e. without providing additional formula feeding) until at least 6 months. Previous studies have suggested that Turkish mothers often combine BF with formula feeding ${ }^{(21,23)}$. Again, these results may reflect the effects of preventive strategies that have been implemented in Child Health Care. In Dutch mothers, however, rates of full BF were low, particularly after 4 months. These lower rates were largely explained by maternal employment status. In the present study, as observed before ${ }^{(31)}$, labour participation was higher among Dutch than among Turkish women. Labour participation 
Table 2. Infant feeding pattern in the study population

(Number of participants and percentages; mean values and standard deviations)

\begin{tabular}{|c|c|c|c|c|c|}
\hline & \multicolumn{2}{|c|}{ Dutch } & \multicolumn{2}{|c|}{ Turkish } & \multirow[b]{2}{*}{$P^{*}$} \\
\hline & $n$ & $\%$ & $n$ & $\%$ & \\
\hline \multicolumn{5}{|l|}{ Duration of full BF (months) } & $<0.001$ \\
\hline$<1$ & 39 & $27 \cdot 3$ & 40 & $28 \cdot 0$ & \\
\hline $1-4$ & 58 & $40 \cdot 6$ & 36 & $25 \cdot 2$ & \\
\hline $4-6$ & 25 & $17 \cdot 5$ & 16 & $11 \cdot 2$ & \\
\hline$\geq 6$ & 21 & $14 \cdot 7$ & 51 & 35.7 & \\
\hline \multicolumn{5}{|l|}{ Start $C F$ including rice flour porridge } & 0.001 \\
\hline$<4$ & 23 & $16 \cdot 1$ & 16 & $11 \cdot 2$ & \\
\hline 4 & 41 & $28 \cdot 7$ & 39 & $27 \cdot 3$ & \\
\hline 5 & 55 & 38.5 & 35 & 24.5 & \\
\hline$\geq 6$ & 24 & $16 \cdot 8$ & 53 & $37 \cdot 1$ & \\
\hline \multicolumn{5}{|l|}{ Start CF excluding rice flour porridge } & $<0.001$ \\
\hline$<4$ & 12 & 8.4 & 11 & $7 \cdot 7$ & \\
\hline 4 & 17 & 11.9 & 39 & $27 \cdot 3$ & \\
\hline 5 & 71 & $49 \cdot 7$ & 35 & 24.5 & \\
\hline$\geq 6$ & 43 & $30 \cdot 1$ & 55 & $40 \cdot 6$ & \\
\hline \multicolumn{6}{|l|}{ Types of complementary foods provided } \\
\hline Fruits & 100 & $69 \cdot 9$ & 102 & $71 \cdot 3$ & 0.897 \\
\hline Vegetables & 70 & $49 \cdot 0$ & 71 & $49 \cdot 7$ & 1.000 \\
\hline Yogurt & 3 & $2 \cdot 1$ & 48 & 33.6 & $<0.001$ \\
\hline Bread, cereals and starches & 17 & 11.9 & 26 & $18 \cdot 2$ & 0.185 \\
\hline Confectionary & 15 & 10.5 & 26 & $18 \cdot 2$ & 0.091 \\
\hline Other & 9 & $6 \cdot 3$ & 55 & 38.5 & $<0.001$ \\
\hline Nothing & 9 & $6 \cdot 3$ & 17 & 11.9 & 0.149 \\
\hline Unknown & 17 & 11.9 & 2 & 1.4 & $<0.001$ \\
\hline \multicolumn{5}{|l|}{ Uncommon foods introduced $<6$ months $†$} & $<0.001$ \\
\hline No & 114 & $79 \cdot 7$ & 85 & $59 \cdot 4$ & \\
\hline Yes & 29 & $20 \cdot 3$ & 58 & $40 \cdot 6$ & \\
\hline \multicolumn{6}{|l|}{ Frequency of milk feeding } \\
\hline Month 1 & 143 & & 139 & & $<0.001$ \\
\hline Mean & \multicolumn{2}{|c|}{7.8} & \multicolumn{2}{|c|}{$9 \cdot 1$} & \\
\hline SD & \multicolumn{2}{|c|}{1.7} & \multicolumn{2}{|c|}{$2 \cdot 0$} & \\
\hline Month 4 & \multicolumn{2}{|c|}{143} & \multicolumn{2}{|c|}{124} & $<0.001$ \\
\hline Mean & \multicolumn{2}{|c|}{$6 \cdot 0$} & \multicolumn{2}{|c|}{$7 \cdot 3$} & \\
\hline SD & \multirow{2}{*}{\multicolumn{2}{|c|}{$143^{1.5}$}} & \multicolumn{2}{|c|}{$2 \cdot 3$} & \\
\hline Month 6 & 143 & & 143 & & $<0.001$ \\
\hline Mean & \multicolumn{2}{|c|}{5.3} & \multicolumn{2}{|c|}{6.1} & \\
\hline SD & \multicolumn{2}{|c|}{1.5} & \multicolumn{2}{|c|}{$2 \cdot 2$} & \\
\hline Frequency CF & & & & & \\
\hline Month 4 & 31 & & 27 & & 0.467 \\
\hline Mean & & & & & \\
\hline SD & & & & & \\
\hline Month 6 & 126 & & 122 & & 0.860 \\
\hline Mean & & & & & \\
\hline SD & & & & & \\
\hline
\end{tabular}

$\mathrm{BF}$, breast-feeding; CF, complementary feeding.

${ }^{*} \chi^{2}$ tests or Fisher's exact test (for two-by-two tables) for categorical variables; Student's $t$ test for continuous variables.

†Uncommon foods are yogurt, bread, cereals and starches; confectionary; and other foods (e.g. soup, meat and cheese)

has been previously shown to affect BF rates in The Netherlands. Maternity leave is 16 weeks, usually divided as 4 weeks before birth and 12 weeks after. Consequently, upon returning to work, 3 months after birth, women are more likely to quit $\mathrm{BF}^{(21)}$.

The labour difference may also explain why Dutch mothers introduce rice flour porridge at an earlier age than Turkish mothers: porridge is commonly given in the evening as a means to help the infant sleep through the night. Indeed, employment status attenuated observed ethnic differences in $\mathrm{CF}$ including rice flour porridge to some extent. The introduction of solids, however, did not differ between the groups, at least not in terms of the current recommendation to start introducing solids between 4 and 6 months of age. At the time of data collection, this recommendation was slightly different: mothers were advised to introduce solids at the age of 6 months but could, after consulting with their Child Health Care physician, start at an earlier age. At that time, mothers were also discouraged from introducing products containing gluten before the age of 6 months. Turkish mothers were generally less likely to adhere to the advice given at that time and to provide their infants with unconventional foods that also included sweet yogurts and cookies. Although there is no evidence that type of foods during weaning affects later $\mathrm{BMI}^{(32)}$, a UK study has suggested 
Table 3. Ethnic differences in infant feeding pattern adjusted for maternal characteristics and perceptions of infant growth (Odds ratios, $\beta$-coefficients and $95 \%$ confidence intervals)

\begin{tabular}{|c|c|c|c|c|c|c|}
\hline & \multicolumn{6}{|c|}{ Turkish $v$. Dutch } \\
\hline & \multicolumn{2}{|c|}{ Model 1} & \multicolumn{2}{|c|}{ Model 2} & \multicolumn{2}{|c|}{ Model 3} \\
\hline & Crude OR & $95 \% \mathrm{Cl}$ & Adjusted OR† & $95 \% \mathrm{Cl}$ & Adjusted OR $\ddagger$ & $95 \% \mathrm{Cl}$ \\
\hline \multicolumn{7}{|l|}{ Duration of full BF§ (months) } \\
\hline$\geq 1$ & $1 \cdot 0$ & $0 \cdot 6,1 \cdot 6$ & 1.0 & $0.5,2 \cdot 0$ & $1 \cdot 0$ & $0.5,2 \cdot 0$ \\
\hline$\geq 4$ & $1.9^{\star}$ & $1 \cdot 2,3 \cdot 0$ & $1 \cdot 2$ & $0 \cdot 6,2 \cdot 2$ & $1 \cdot 1$ & $0 \cdot 6,2 \cdot 2$ \\
\hline$\geq 6$ & $3 \cdot 2^{*}$ & $1 \cdot 8,5 \cdot 7$ & $2 \cdot 1^{*}$ & $1 \cdot 0,4 \cdot 3$ & $2 \cdot 0$ & $1 \cdot 0,4 \cdot 3$ \\
\hline \multicolumn{7}{|c|}{ Introduction CF including rice flour porridge || (months) } \\
\hline$<4$ & 0.9 & $0.4,1 \cdot 8$ & 0.4 & $0 \cdot 1,1 \cdot 1$ & 0.4 & $0 \cdot 1,1 \cdot 0$ \\
\hline$\geq 6$ & $2 \cdot 9^{*}$ & $1 \cdot 6,5 \cdot 1$ & $2 \cdot 4^{*}$ & $1 \cdot 1,4 \cdot 9$ & $3 \cdot 1^{*}$ & $1 \cdot 4,6 \cdot 7$ \\
\hline \multicolumn{7}{|c|}{ Introduction CF excluding rice flour porridge\| (months) } \\
\hline$<4$ & $1 \cdot 1$ & $0.5,2.6$ & 0.8 & $0.3,2.5$ & 0.7 & $0 \cdot 2,2 \cdot 2$ \\
\hline$\geq 6$ & $1 \cdot 6$ & $1 \cdot 0,2 \cdot 6$ & 1.5 & $0 \cdot 8,2 \cdot 8$ & $1 \cdot 8$ & $0 \cdot 9,3 \cdot 3$ \\
\hline \multirow[t]{2}{*}{ Uncommon foods $<6$ months $\|^{* *}$} & $2 \cdot 7^{\star}$ & $1 \cdot 6,4 \cdot 6$ & $2 \cdot 1^{*}$ & $1 \cdot 1,4 \cdot 3$ & $2 \cdot 0$ & $1 \cdot 0,4 \cdot 1$ \\
\hline & Crude $\beta$ & $95 \% \mathrm{Cl}$ & Adjusted $\beta \dagger$ & $95 \% \mathrm{Cl}$ & Adjusted $\beta \ddagger$ & $95 \% \mathrm{Cl}$ \\
\hline \multicolumn{7}{|l|}{ Frequency of feedingt† } \\
\hline Milk feeding month 1 & $1 \cdot 3^{*}$ & $0.8,1 \cdot 7$ & $1 \cdot 1^{*}$ & $0.6,1 \cdot 7$ & $1 \cdot 2^{*}$ & $0 \cdot 6,1 \cdot 8$ \\
\hline Milk feeding month 4 & $1 \cdot 2^{*}$ & $0.8,1 \cdot 7$ & $0.9^{\star}$ & $0.3,1.5$ & $1 \cdot 0^{*}$ & $0.4,1.6$ \\
\hline Milk feeding month 6 & $0.9^{*}$ & $0.4,1.3$ & 0.3 & $-0.3,0.8$ & 0.4 & $-0 \cdot 2,1 \cdot 0$ \\
\hline CF month 4 & -0.3 & $-1 \cdot 0,0.4$ & -0.3 & $-1 \cdot 0,0.4$ & -0.5 & $-1 \cdot 3,0.3$ \\
\hline CF month 6 & -0.0 & $-0.4,0.3$ & $0 \cdot 1$ & $-0.3,0.4$ & 0.0 & $-0.3,0.4$ \\
\hline
\end{tabular}

BF, breast-feeding; CF, complementary feeding.

* Significant association $(P<0.05)$.

†Full BF and frequency of milk feeding adjusted for maternal weight status, parity and employment; introduction to CF including rice flour porridge adjusted for maternal age and employment; introduction of CF excluding rice flour porridge adjusted for maternal age and parity; intake of unconventional CF $<6$ months adjusted for maternal age, parity and employment; frequency of CF adjusted for parity.

$\ddagger$ Additionally adjusted for perceptions of growth.

$\S$ Logistic regression analyses on cumulative categories, accounting for ordinality of the data.

II Multinomial regression analysis, reference category is introduction at 4-6 months.

I Uncommon foods are yogurt, bread, cereals and starches; confectionary; and other foods (e.g. soup, meat and cheese).

${ }^{* *}$ Logistic regression analysis, reference category is no intake of uncommon foods $<6$ months.

†† Linear regression analysis.

that adhering to dietary guidelines is an indication of a healthier family diet, in general, and can affect lean mass at the age of 4 years ${ }^{(32,33)}$. More information on family diet could thus be important in the development of effective interventions for childhood overweight and obesity; however, unfortunately, we were no able to follow-up on the infant and family diet in the present study.

To our knowledge, only one other study has investigated ethnic differences in infant feeding frequency ${ }^{(34)}$, and has found Hispanic 4- to 5-month-old infants to have one feeding per $d$ more than non-Hispanic infants. Feeding frequently when food is available is a traditional feeding practice, which, just like other traditional practices as providing preferred foods or large portions, may affect obesity risk ${ }^{(35)}$. In the present study, Turkish infants were fed on average one milk feeding per $\mathrm{d}$ more than Dutch infants, at each measurement period (1, 4 and 6 months). This difference was independent from the type of feeding (full BF or full formula feeding). At the age of 6 months, the difference was partly explained by maternal employment status: additional analyses revealed that unemployed Turkish mothers still provided one more milk feeding per d but employed Turkish mothers did not (data not shown). The present results may suggest that, in general, Turkish mothers use infant food for comforting more often than Dutch mothers, as was observed before $^{(24)}$. If so, this could be a starting point of a dietary pattern in which children are provided with comforting foods throughout the day rather than a dietary pattern in which eating moments are structured. The results of the Dutch national food consumption survey also suggest that this could be a potential problem: already one in every five children has eight or more eating moments during the day and $24 \%$ of the daily energy consumption are sweet products such as confectionary ${ }^{(36)}$.

An important strength of the present study is that the present study design enables us to include a minority group that is normally difficult to include in research, and established high response and low dropout rates. Moreover, the sociodemographic characteristics of the fourteen mothers that dropped out were similar to the characteristics of the participating mothers: $50 \%$ were of Turkish ethnic background; $28 \%$ lower educated; $50 \%$ multiparous; $57 \%$ employed. Nevertheless, the final sample size of the present study may be considered small. Our initial power analysis was based on an expected difference in growth between the ethnic groups, as we also aimed to assess growth differences in relation to feeding practices; results of that study have been submitted (JE Jansen, MLA de Kroon and MCM Meijers, unpublished results). According to that power calculation, a sample size of 132 per group would suffice to establish a $0 \cdot 4$ difference in standard deviation scores in weight. Also based on previous studies ${ }^{(21-24)}$, we had expected larger differences 
in feeding practices than observed. Given the sample size and relatively small differences, we choose only to adjust for covariables that were significantly associated with both ethnicity and feeding practices. Although maternal educational level was associated with both, we choose not to adjust for this variable. Initial analysis revealed that the correlation between ethnicity and education was large $(-0.75)$, implying that Turkish women were generally less educated and Dutch women were generally highly educated. As a result, we cannot be certain that the differences that pertained are, in fact, not educational differences. However, if we compare the small group of Turkish higher-educated women with both Turkish lower-educated women and Dutch higher-educated women, they resemble the first much more than the latter, e.g. in duration of full BF (Turkish highly educated, 44\%; Turkish less educated, 34\%; Dutch highly educated, 19\%) and normalweight status (Turkish highly educated, 17\%; Turkish less educated, 19\%; Dutch highly educated, 50\%). This suggests that the differences may be related more to culture than to education. To account for differences in language proficiency, we interviewed mothers in their language of choice, which enabled us to collect detailed information on feeding practices that have not been investigated previously (such as feeding frequency). However, the study was designed to investigate infant feeding practices only at three time points during the first 6 months of life. Future studies would benefit from a longer duration of follow-up, at least until 12 months considering that the period of 6 to 12 months, or even 24 months is an important period of transition from weaning to the family diet, potentially affecting lifelong eating habits ${ }^{(32,35)}$.

In summary, the present study showed some important ethnic differences in feeding practices, which were, however, hardly affected by perceptions of growth. Increasing mothers' knowledge of healthy feeding practices, irrespective of infant weight management, may thus have potential as preventive strategy in Child Health Care. Beneficial components of early feeding practices among Turkish mothers are a long duration of full $\mathrm{BF}$ and a timely (between 4 and 6 months) introduction of CF. However, Turkish mothers feed their children more often during the day and do not appear restrictive with respect to types of foods given during weaning. Prevention tailored to Turkish mothers in Child Health Care should include discussing choices of complementary foods and frequency of feeding from an early age onwards. In Dutch mothers, support for the continuation of $\mathrm{BF}$ remains an important issue.

\section{Supplementary material}

To view supplementary material for this article, please visit http://dx.doi.org/10.1017/S0007114515000951

\section{Acknowledgements}

The present study was financially supported by the Research \& Development Fund of the Public Health Service of Amsterdam. We gratefully acknowledge the advice of Dr Marcel F. van der Wal in the design and data collection phases of the study.
We thank all participating mothers, medical students and Child Health Care Centre workers.

The authors' responsibilities are as follows: M. v. E. performed the statistical analyses and wrote the manuscript; C. M. C. M. coordinated and T. G. M. V. supervised the data collection; M. L. A. d. K. and T. G. M. V. provided statistical advice; J. E. J. assisted with data cleaning. All authors contributed to the interpretation of the data and revision of the manuscript.

The authors declare that there is no conflict of interest.

\section{References}

1. Wang Y \& Lobstein T (2006) Worldwide trends in childhood overweight and obesity. Int J Pediatr Obes 1, 11-25.

2. International Association for the Study of Obesity (2013) Childhood overweight \% (including obesity) by region. http://www.iaso.org/site_media/library/resource_images/ Global_Childhood_Overweight_October_2013.pdf (accessed December 2013).

3. Biro FM \& Wien M (2010) Childhood obesity and adult morbidities. Am J Clin Nutr 91, Suppl. 5, S1499-S1505.

4. Singh AS, Mulder C, Twisk JWR, et al. (2008) Tracking of childhood overweight into adulthood: a systematic review of the literature. Obes Rev 9, 474-488.

5. Steinberger J, Daniels SR, Eckel RH, et al. (2009) Progress and challenges in metabolic syndrome in children and adolescents: a scientific statement from the American Heart Association Atherosclerosis, Hypertension, and Obesity in the Young Committee of the Council on Cardiovascular Disease in the Young; Council on Cardiovascular Nursing; and Council on Nutrition, Physical Activity, and Metabolism. Circulation 119, 628-647.

6. Saxena S, Ambler G, Cole TJ, et al. (2004) Ethnic group differences in overweight and obese children and young people in England: cross sectional survey. Arch Dis Child $\mathbf{8 9}, 30-36$

7. Kolsgaard ML, Andersen LF, Tonstad S, et al. (2008) Ethnic differences in metabolic syndrome among overweight and obese children and adolescents: the Oslo Adiposity Intervention Study. Acta Peadiatr 97, 1557-1563.

8. Singh GK, Siahpush M \& Kogan MD (2010) Rising social inequalities in US childhood obesity, 2003-2007. Ann Epidemiol 20, 40-52.

9. Will B, Zeeb H \& Baune BT (2005) Overweight and obesity at school entry among migrant and German children: a cross-sectional study. BMC Public Health 5, 45.

10. Brug J, van Stralen MM, Chinapaw MJM, et al. (2012) Differences in weight status and energy-balance related behaviours according to ethnic background among adolescents in seven countries in Europe: the ENERGY-project. Pediatr Obes 7, 399-411.

11. De Wilde JA, Verkerk PH \& Middelkoop BJC (2014) Declining and stabilising trends in prevalence of overweight and obesity in Dutch, Turkish, Moroccan and South Asian children 3-16 years of age between 1999 and 2011 in the Netherlands. Arch Dis Child 99, 46-51.

12. Schönbeck Y, Talma H, van Dommelen P, et al. (2011) Increase in prevalence of overweight in Dutch children and adolescents: a comparison of nationwide growth studies in 1980, 1997 and 2009. PLoS One 6, e27608.

13. van Vliet M, von Rosenstiel IA, Schindhelm RK, et al. (2009) Ethnic differences in cardiovascular risk profile in an overweight/obese paediatric cohort in the Netherlands: a cross-sectional study. Cardiovasc Diabetol 8, 2. 
14. De Hoog MLA, van Eijsden M, Stronks K, et al. (2012) Association between body size and blood pressure in children from different ethnic origins. Cardiovasc Diabetol 11, 136.

15. Baker JL, Michaelsen KF, Rasmussen KM, et al. (2004) Maternal prepregnant body mass index, duration of breastfeeding, and timing of complementary food introduction are associated with infant weight gain. Am J Clin Nutr $\mathbf{8 0}$, $1579-1588$.

16. Gunnarsdottir I, Schack-Nielsen L, Michaelsen KF, et al. (2010) Infant weight gain, duration of exclusive breastfeeding and childhood BMI - two similar follow up cohorts. Public Health Nutr 13, 201-207.

17. Arenz S, Ruckerl R, Koletzko B, et al. (2004) Breast-feeding and childhood obesity - a systemic review. Int J Obes $\mathbf{2 8}$ 1247-1256.

18. Schrack-Nielsen L, Sorensen TI, Mortensen EL, et al. (2010) Late introduction of complementary feeding, rather than duration of breastfeeding, may protect against adult overweight. Am J Clin Nutr 91, 619-627.

19. Pearce J, Taylor MA \& Langley-Evans SC (2013) Timing of the introduction of complementary feeding and risk of childhood obesity: a systematic review. Int J Obes 37, 1295-1306.

20. Beyerlein A \& von Kries R (2011) Breastfeeding and body composition in children, will there ever be conclusive empirical evidence for a protective effect against overweight? Am J Clin Nutr 94, Suppl. 6, 1772S-1775S

21. Bulk-Bunschoten AM, Pasker-de Jong PC, van Wouwe JP, et al. (2008) Ethnic variation in infant-feeding practices in the Netherlands and weight gain at 4 month. J Hum Lact 24, 42-49.

22. Demirtas B, Ergocmen B \& Taskin L (2011) Breastfeeding experiences of Turkish women. J Clin Nurs 21, 1109-1118.

23. Yazgan H, Yazgan Z, Keleş E, et al. (2013) The effect of family members on breastfeeding practices among Turkish mothers. Breastfeed Med 8, 232.

24. Hulsmann AR, Senyurek A \& Oostenbrink R (2005) Verschillen in voedingsgewoonten in het eerste levensjaar tussen Turkse en Nederlandse zuigelingen (Differences in dietary habits in the first year of life between Turkish and Dutch infants). Tijdschr Kindergeneesk 73, 6-9.
25. L'Hoir MP, Boere-Boonekamp MM, Beltman M, et al. (2006) Preventie van overgewicht bij niet-westerse zuigelingen (Prevention of overweight among infants of non-Western descent). Tijdschrift voor Jeugdgezondheidszorg 5, 89-92.

26. Doolen J, Alpert PT \& Miller SK (2009) Parental disconnect between perceived and actual weight status of children: a metasynthesis of the current research. J Am Acad Nurse Pract 21, 160-166.

27. De Hoog MLA, Stronks K, van Eijsden M, et al. (2012) Ethnic differences in maternal underestimation of offspring's weight: the ABCD study. Int J Obes 36, 53-60.

28. Lanting CI, Heerdink-Obenhuijsen N, Schuit-van Raamsdonk HLL, et al. (2013) JGZ-richtlijn voeding en eetgedrag (Child Health Care Guideline on Nutrition and Eating Behavior). Utrecht: Nederlands Centrum Jeugdgezondheid.

29. Talma H, Schönbeck Y, Bakker B, et al. (2010) Groeidiagrammen 2010 (Growth Charts 2010). Leiden: TNO Kwaliteit van Leven.

30. Brant R (1990) Assessing proportionality in the proportional odds model for ordinal logistic regression. Biometrics $\mathbf{4 6}$, $1171-1178$

31. Kok S, Bosch N, Deelen A, et al. (2011) Migrant Women on the Labour Market. On the Role of Home- and Host-country Participation. The Hague: CPB Netherlands Bureau for Economic Policy Analysis (CPB discussion paper 180).

32. Pearce J \& Langley-Evans SC (2013) The types of food introduced during complementary feeding and risk of childhood obesity: a systematic review. Int J Obes 37, 477-485.

33. Robinson SM, Marriott LD, Crozier SR, et al. (2009) Variations in infant feeding practice are associated with body composition in childhood: a prospective cohort study. J Clin Endocrinol Metab 94, 2799-2805.

34. Ziegler P, Hanson C, Ponza M, et al. (2006) Feeding infants and toddlers study: meal and snack intakes of Hispanic and non-Hispanic infants and toddlers. J Am Diet Assoc 106, S107-S123.

35. Birch LL \& Doub AE (2014) Learning to eat: birth to age 2 y. Am J Clin Nutr 99, 723S-728S.

36. Ocké MC, van Rossum CTM, Fransen HP, et al. (2008) Dutch National Food Consumption Survey - Young Children 2005/ 2006. RIVM-rapport 350070001. Bilthoven: RIVM. 